\title{
CRIANÇAS DE DOIS ANOS DE IDADE COMO COCONSTRUTORAS DE CULTURA ${ }^{2} 3$
}

\section{Niina Rutanen}

Resumo: De que maneira a cultura é coconstruída no nível micro das interações diárias em uma creche? O que é a "cultura" que está sendo construída, quem são os construtores e como o fazem? Este artigo se baseia em um estudo de caso de interação de crianças de dois anos de idade. Para o estudo, gravações em vídeo foram feitas duas vezes por mês durante um período de sete meses em uma creche na Finlândia. Nas sessões de gravação, as crianças recebiam alguns objetos para brincar. Quatro sessões foram selecionadas para a análise qualitativa. Durante a primeira sessão, as crianças produziram uma contracultura às tentativas da professora de estruturar a situação. Gestos, posturas e verbalizações entre as crianças surgiram de movimentos inicialmente aleatórios. $\mathrm{O}$ significado e as funções dessas posturas, movimentos e sons mudaram durante o andamento das ações. Alguns dos movimentos e verbalizações foram restabelecidos e mais elaborados nas sessões de gravação seguintes. As circunscrições para as ações foram constantemente negociadas verbalmente e não verbalmente entre as crianças e os adultos. A cultura institucional mais ampla da educação infantil não constituía uma estrutura passiva externa ao andamento das ações, mas ganhava concretude nas situações do aqui-e-agora. As expectativas e intenções dos adultos materializavam-se nas iniciações e nos ajustes do ambiente e canalizavam as possibilidades de ação das crianças. Baseando-se nisso, as crianças coconstruíam movimentos e significados novos fora da esfera de expectativa dos adultos.

Palavras-chave: Interação criança-criança. Crianças. Coconstrução de cultura. Creche.

1 O artigo foi originalmente publicado no periódico European Early Childhood Education Research (2007), 15(1), 59-69.

2 Tradução de Carolina Brum e revisão técnica de Fernanda Müller e Ana Carvalho.

3 Gostaria de agradecer ao National Research and Development Centre for Welfare and Health in Finland por fornecer os recursos e o acesso ao campo nos estágios iniciais do projeto. Também sou grata ao Research Council of Norway pelo financiamento da pesquisa e ao Institute of Psychology, da Norwegian University of Science and Technology (NTNU) por me fornecer condições de trabalho enquanto preparava este artigo. 


\section{Introdução}

A literatura sobre psicologia do desenvolvimento e educação infantil inclui uma variedade grande de abordagens para conceituar e investigar a interação das crianças pequenas (Rutanen, 2005). Este trabalho filia-se principalmente às abordagens que enfatizam a natureza dialógica da constituição humana (Amorim, 2002; Fogel, 1993; Fogel, Koeyer, Bellagamba, \& Bell, 2002; Hermans \& Kempen, 1995; Pedrosa, 1989; Rossetti-Ferreira, Amorim, Silva, \& Carvalho, 2004). Em sintonia com os trabalhos de duas pesquisadoras brasileiras, Isabel Pedrosa e Ana Almeida Carvalho (Carvalho, ImperioHamburger, \& Pedrosa, 1998; Pedrosa, 1989; Pedrosa, Carvalho, \& ImperioHamburger, 1997), uma metáfora de campo é aplicada no contexto teórico. Ao invés de discutir a interação das crianças como uma relação de troca mútua, o foco é posicionado na interpretação do espaço psicológico interindividual dos sujeitos.

Este artigo enfocará a análise qualitativa de situações interativas particulares entre crianças em uma creche na Finlândia. A questão aqui levantada lida com a coconstrução de cultura. Como isso ocorre no nível micro das interações das crianças? O que é a cultura que está sendo construída e quem são os construtores e como o fazem?

\section{O exemplo de caso e o procedimento metodológico}

A creche selecionada para o estudo participava do projeto nacional Luma Young Children's Mathematics and Natural Sciences, coordenado pelo National Research Centre for Welfare and Health in Finland (Centro Nacional de Pesquisa para o Bem-Estar e Saúde na Finlândia - 1997-1999). Atendendo aos objetivos do projeto Luma, a professora da pré-escola e da creche apresentaram um projeto colaborativo de aprendizagem com crianças sobre o tema "Água" e dividiram o grupo em grupos menores de quatro crianças. Gravações em vídeo foram feitas no centro durante um ano acadêmico, aproximadamente duas vezes ao mês. Nas situações de gravação, a professora colocava alguns objetos sobre a mesa ou sobre o chão e convidava um pequeno grupo de crianças "para fazer coisas" e/ou "brincar" com eles. Dado o interesse na continuidade de elaboração do projeto Água, a professora frequentemente fornecia água em bacias. No total, 33 sessões de gravação ocorreram durante esse ano, com duração entre 5 e 40 minutos. A intenção geral era observar o que acontece nessas situações: como as crianças interagem com outras e com os objetos fornecidos.

A partir desse corpus de material, quatro sessões com uma dupla de crianças de dois anos de idade foram selecionadas para análise interpretativa e qualitativa (Oliveira \& Rossetti-Ferreira, 1996; Pedrosa \& Carvalho, 2005; Valsiner, 1997). A análise lida com mudanças em dois níveis: em pri- 
meiro lugar, alguns momentos específicos de mudança são interpretados no contexto do andamento das ações na sessão de gravação; em segundo lugar, essas mudanças são discutidas em relação a outras sessões de gravação com as mesmas crianças durante aquele ano.

\section{O andamento das ações entre crianças durante a primeira sessão}

A primeira sessão de gravação com Martti ( 2 anos e 7 meses, menino) e Heidi ( 2 anos e 9 meses, menina) ocorreu na sala onde as crianças geralmente fazem sua sesta diária. Como de costume, havia um sofá e uma cama pequena nessa sala. A professora havia colocado uma pequena mesa e duas cadeirinhas no centro da sala (Figura 1). Uma bacia transparente cheia de água estava em cima da mesa. Uma câmera de vídeo, sobre um tripé, estava no canto da sala. A pesquisadora (NR) já estava na sala quando as crianças e a professora entraram. Após ligar a câmera, os dois adultos sentaram-se no chão perto do tripé. A duração da sessão foi de 36 minutos.

As crianças entram na sala juntamente com a professora. A professora afasta um pouco as cadeiras da mesa e convida as crianças para sentar e brincar. As crianças sentam-se em silêncio e olham ao redor. Elas também olham a bacia cheia de água. A professora e a pesquisadora mantêm-se em silêncio - com exceção de alguns poucos comentários da professora -, observando a situação. Após oito minutos olhando ao redor, as crianças começam a fazer caretas e acenar com as mãos uma para o outra. Após cinco minutos, o movimento de suas mãos é elaborado em uma brincadeira de pegar "algo" do chão, oferecê-lo ao outro e comê-lo. As crianças oferecem coisas umas às outras, pegam-nas e se recusam a pegar. Elas riem e produzem sons, mas utilizam apenas poucas palavras até o fim da sessão. A exceção é o som "kokaa"4 que elas começam a repetir e com a qual brincam após 16 minutos. A professora coloca pratos e copos na mesa após 30 minutos, mas as crianças continuam a brincar sem eles.

A característica perceptivamente mais saliente, considerando-se a sessão inteira, é a elaboração de uma brincadeira de dar-e-receber pelas crianças. As crianças não tinham brinquedos ou outro objeto material, mas elas coconstruíram a brincadeira com seus olhares, cabeça, movimentos das mãos e da boca, e sons. A partir de movimentos aleatórios de olhar ao redor, surgiram os primeiros movimentos da cabeça e do rosto que levaram a um recorte consensual (Fogel, 1993) de atenção mútua entre eles. Depois disso, novos elementos (como movimentos com a mão em direção à boca) foram introduzidos. Somente depois de 16 minutos Martti sussurra um primeiro som relacionado à brincadeira; de debaixo da mesa surgiu algo a ser dado por Martti e recebido/comido por Heidi.

4 Não tem sentido, como palavra, em finlandês. 


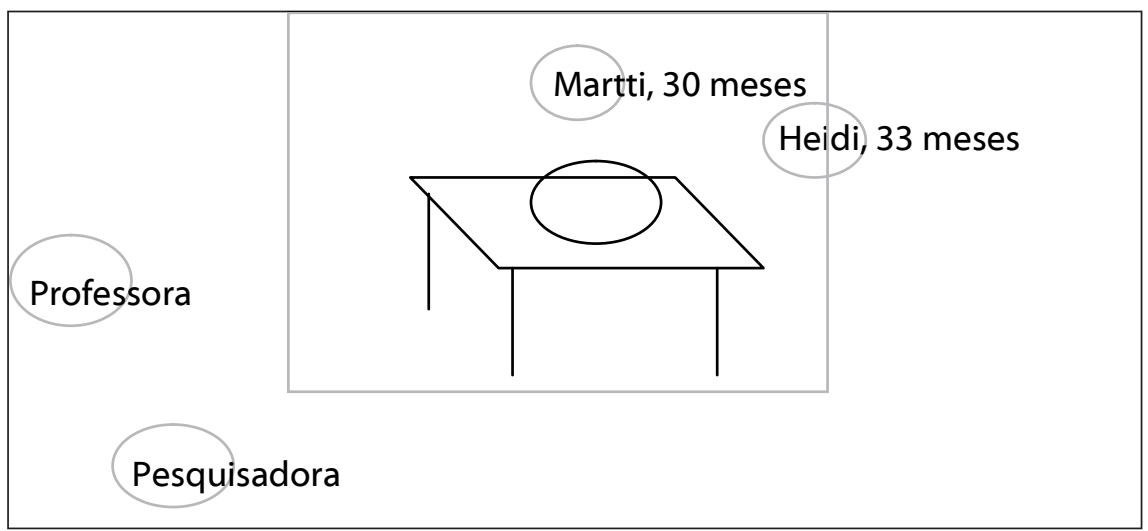

Figura 1. O ambiente da primeira sessão de gravação. A professora e a pesquisadora não são visíveis na tela do víde.

As ações das crianças eram correguladas; elas emergiam em relação às ações do outro (Fogel, 1993; Carvalho et al, 1998; Pedrosa et al, 1997). As crianças construíram a ação conjunta recortando com suas ações as ações do outro (Pedrosa, 1989). Esse ajustamento das ações às do outro ocorreu pela repetição das ações parcial ou integralmente, pela adição de alguma coisa ou pela substituição de algumas ações do outro. As crianças usaram principalmente meios não-verbais.

Ao longo da sessão, Martti reintroduziu várias vezes o gesto de oferecer e/ou pegar, como que usando isso como estratégia para retornar aos movimentos previamente elaborados. Além disso, as verbalizações de Martti começaram a representar uma ação compartilhada e uma configuração particular nesse campo de interação; em outras palavras, suas verbalizações adquiriram um "efeito realizador". Ao fazer o som "koka kokaa" havia uma probabilidade crescente de a ação ser mantida por ambos. Durante a sessão, as palavras e a configuração total do fluxo das ações (pegar do chão, oferecendo, abrir a boca, colocar na boca, mastigar, rir alto) transformaram-se, de informações suspensas e aleatórias no campo de interação, em significados compartilhados (Pedrosa et al., 1997)."Koka kokaa" tornou-se a expressão linguística que representou as ações em outro nível de significado.

Embora envolvidas em ajustamentos mútuos, as crianças alternavam a atenção para outros aspectos do ambiente. Elas não eram uma entidade isolada, mas um sistema aberto: o fluxo de ações ajustava-se a vários elementos da situação, como, por exemplo, aos sons de fora da sala e aos movimentos dos adultos. 


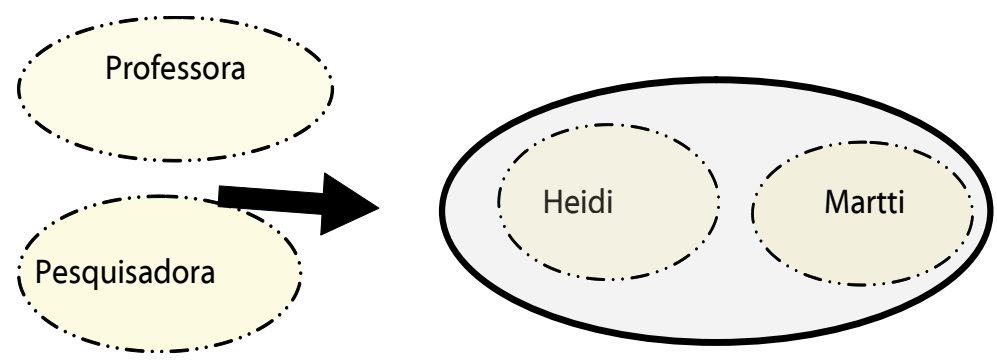

Figura 2. As crianças como alvos de observação.

\section{Um passo adiante: o papel dos adultos?}

Com base nas observações preliminares do material, tornou-se claro que para entender as ações das crianças era importante incluir na análise o contexto social-cultural-ideológico e o papel dos adultos Ao invés de posicionar as crianças como sujeitos do estudo, no sentido de serem alvos das observações dos adultos (Figura 2), tentei dar sentido à complexa rede de regulações para entender o que está acontecendo entre as crianças.

No começo da sessão, a professora apresentou uma orientação sobre os eventos que se seguiriam: "Agora vocês podem brincar", ela disse. Quando as crianças permaneceram sentadas e olharam ao redor silenciosamente sem tocar na água, a professora reagiu à situação com uma nova sugestão. Ela sussurrou: "O que é isto?", as crianças responderam: "Água".Do ponto de vista da professora, as crianças não responderam suficientemente com seus movimentos ou verbalizações. Diante disso, a professora foi misturar a água na bacia. As crianças mantiveram suas mãos paradas. Elas olharam para a professora, para a pesquisadora e para a bacia.

As crianças pareciam querer dar sentido ao que estava acontecendo na situação e quais eram as intenções e expectativas dos adultos. Elas resistiram silenciosamente às iniciações dos adultos e não se comprometeram em manipular os objetos materiais que os adultos forneceram para elas "brincarem". Elas protestaram com seus corpos às tentativas da professora de reestruturar a situação e de ter a bacia de água como a figura principal da situação.

Durante a sessão, os movimentos aleatórios das crianças (alongandose e curvando-se em direção ao chão e ao outro) levaram à coconstrução de uma atividade conjunta dentro dos circunscritores (limites/possibilidades) (Valsiner, 1997) do espaço físico que as cadeiras e a mesa forneciam. O conteúdo simbólico das ações, "comer" e oferecer "comida", surgiram nesse 
ambiente, que proporcionou essa atividade também por conteúdo simbólico: o ambiente incluía mesa e cadeiras, como na hora das refeições. As cadeirinhas estavam tão próximas da mesa que as crianças não podiam se levantar sem afastá-las dela; apesar disso, as crianças sentaram-se perto o suficiente para conseguirem alcançar o rosto um do outro.

As ações das crianças de não tocarem na água canalizaram as observações e tentativas da professora de reestruturar o ambiente na direção de que as crianças elaborassem um "brincar com água."As ações da professora indicaram o que deveria acontecer: esperava-se que as crianças viessem, sentassem e tocassem a água na bacia. Entendia-se que as crianças seriam criativas, barulhentas e ativas - se lhes fosse dado espaço para isso. Esperava-se que "brincar" incluísse: 1) manipulação dos objetos oferecidos; 2) uso de linguagem verbal incluindo alguma referência aos objetos oferecidos; e 3) atenção das crianças para o outro, para os objetos e para o uso dos objetos pelo outro, ao invés de atenção para os adultos.

Nessa situação, os adultos encararam um dilema: foi fornecido às crianças o direito de se dedicarem à "brincadeira livre", mas supunha-se que a brincadeira livre necessariamente surgiria juntamente com a manipulação conjunta dos objetos oferecidos. Assim sendo, a professora empenhou-se na renegociação dos limites da brincadeira no sentido de que "livre" não significava que as crianças estavam livres para não tocar a água. Ainda que "brincadeira livre" seja um termo amplamente usado na literatura sobre educação infantil, sugiro que não existe uma brincadeira livre como oposição a "não-livre", mas que a brincadeira sempre ocorre em relação a alguma circunscrição (Rutanen, 2004). Os adultos circunscrevem a brincadeira ao arrumar o ambiente e ao estar presentes, mas as crianças também circunscrevem a brincadeira entre elas. A brincadeira surge dentro dos limites/possibilidades do campo coconstruído.

\section{Como atribuir sentido à complexidade das situações?}

A Figura 3 ilustra alguns dos elementos que constituíram o contexto das negociações nas situações do aqui-e-agora.

Embora os participantes das sessões de gravação tenham sido Heidi, Martii, a professora e a pesquisadora, vários outros participaram das situações indiretamente. As crianças participantes frequentavam a creche antes da intervenção. Como já estavam familiarizadas umas com as outras, seu passado incluía uma história de coajustamentos entre elas. Pode-se supor que elas já tinham se envolvido em negociações de diversas posições e significados (Pedrosa, 1989): que tinham criado recortes convergentes (Branco, 1998) para ações, assim como participado com outras crianças da construção da cultura de pares com rotinas, códigos e significados particulares (Corsaro, 2005). 


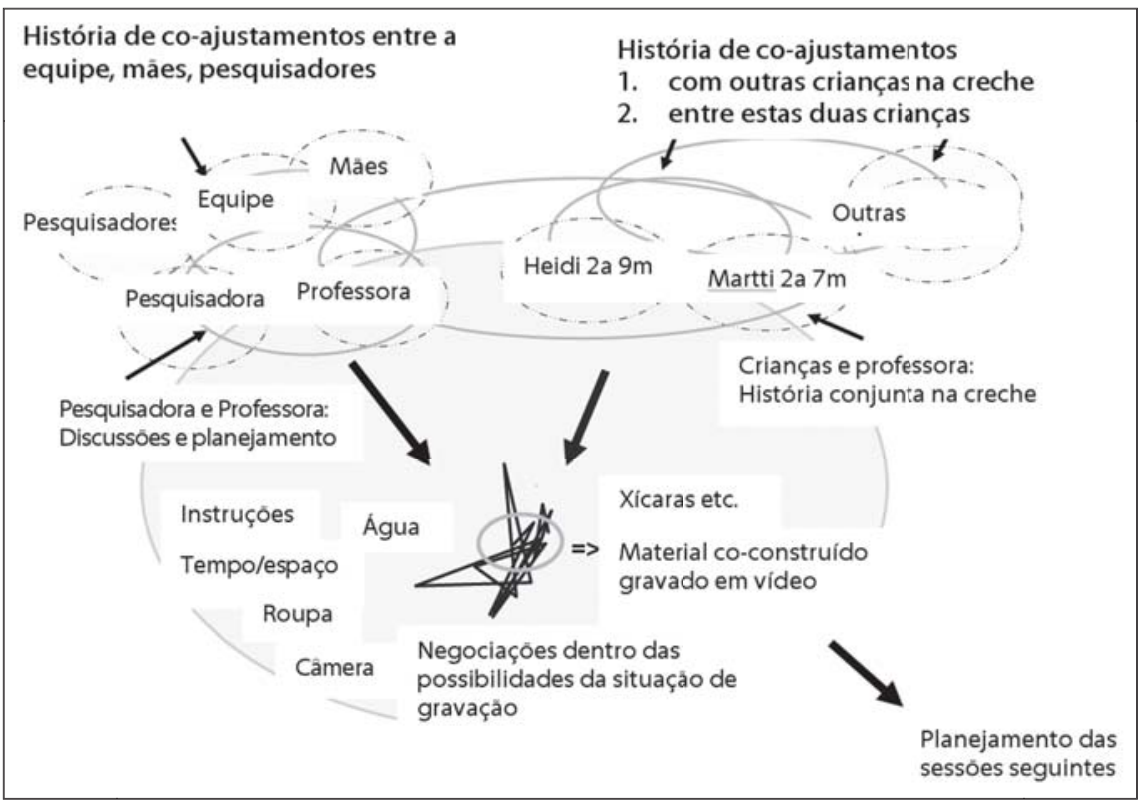

Figura 3. Negociações antes, durante e depois da primeira sessão de gravação.

As crianças participantes também tinham uma história conjunta com a professora: já tinham se envolvido previamente em vários coajustamentos com ela. Ambas as crianças tinham ainda suas próprias expectativas, observações, intenções e percepções, relacionadas aos diferentes aspectos das situações:ambas tinham sua história particular e sua posição subjetiva, corporalmente assimilada (ponto de vista) dentro da situação.

O grupo de pesquisa, os outros funcionários da creche e as mães participaram das discussões sobre como organizar as situações. Antes da primeira gravação, o elo entre as crianças e a pesquisadora havia sido as discussões com a equipe, com as mães das crianças e, particularmente, com a professora. Tal como as crianças, todos os adultos envolvidos tinham expectativas e intenções diversas em relação ao projeto.

As intenções e expectativas dos adultos foram materializadas no arranjo do ambiente, isto é, as possibilidades/limites oferecidos para as ações das crianças (ver "agenda básica", Kindermann \& Valsiner, 1989). Os arranjos canalizaram as possibilidades de ações das crianças em certas direções, mesmo que as ações não fossem determinadas pelo ambiente (Valsiner, 1997).

No decorrer da sessão, novamente, as expectativas dos adultos sobre o que deveria acontecer em um estudo de interação das crianças criaram as tentativas de canalizar as ações das crianças em certas direções, mesmo que não claramente definidas. As ações das crianças de resistência e co- 
construção de ações e significados com movimentos dos olhos e mãos e verbalizações produziram uma contracultura (Rönnberg, 2005) em relação às tentativas de estruturação dos adultos. As crianças engajaram-se ativamente na definição da situação ao introduzirem novidades fora do campo de expectativas dos adultos. Nesse sentido, as crianças participaram na reconstrução das concepções iniciais dos adultos por meio de suas ações na situação de pesquisa.

Os adultos revisaram as expectativas, objetivos e concepções sobre crianças, brincadeira e pesquisa e planejaram as sessões seguintes de gravação juntamente com outros participantes indiretos (grupo de pesquisa, outros funcionários, mães). Seleções foram feitas continuamente em relação a que salas deveriam ser usadas para as gravações, quais objetos fornecer, como iniciar as situações e onde focalizar a câmera.

\section{O encadeamento das sessões de gravação}

As sessões de gravação começaram a formar um encadeamento de situações estruturadas de maneira aproximadamente similar (Figura 4). Dentro da variabilidade, alguns dos elementos constantes eram: a câmera, a ausência de outras crianças e a atenção dos adultos às crianças. Essas circunscrições situacionais possibilitaram as ações das crianças e a construção de novidade dentro das sessões repetidas de gravação. A gravação em vídeo, registrada em fita, foi apenas um pequeno recorte do complexo fluxo de eventos ocorrido.

Nas sessões de gravação, ocorreram inversões nas posições dos participantes - as crianças observaram os adultos, ainda que o ponto de partida inicial para os adultos tivesse sido observar as crianças. As crianças olhavam os adultos, assinalavam a presença dos adultos no fluxo, e os convidavam para se agregar ainda mais visivelmente à situação. Os adultos foram posicionados pelas crianças como participantes do fluxo de ações.

Em suma, ao longo do ano, Heidi, Martii, a professora e a pesquisadora participaram da criação de uma história conjunta das sessões de gravação que constituía o pano de fundo antes de cada nova sessão. Todos tinham alguma expectativa com base em sessões anteriores sobre o que eram as situações, o que poderia ocorrer e o que seria improvável que ocorresse. Quando a câmera foi trazida para o Centro, as crianças e a professora já sabiam que eles logo estariam fazendo "coisas com água"; o que estava incluído na prática dentro dos limites de "coisas com água" era algo que Heidi, Martii, a professora e a pesquisadora construíram conjuntamente nas várias sessões.

Os participantes das situações também haviam coconstruído um amplo leque de significados em relação à água; a água havia ganhado uma posição de ator não-humano (Latour, 1996) nas sessões: a água fazia coi- 


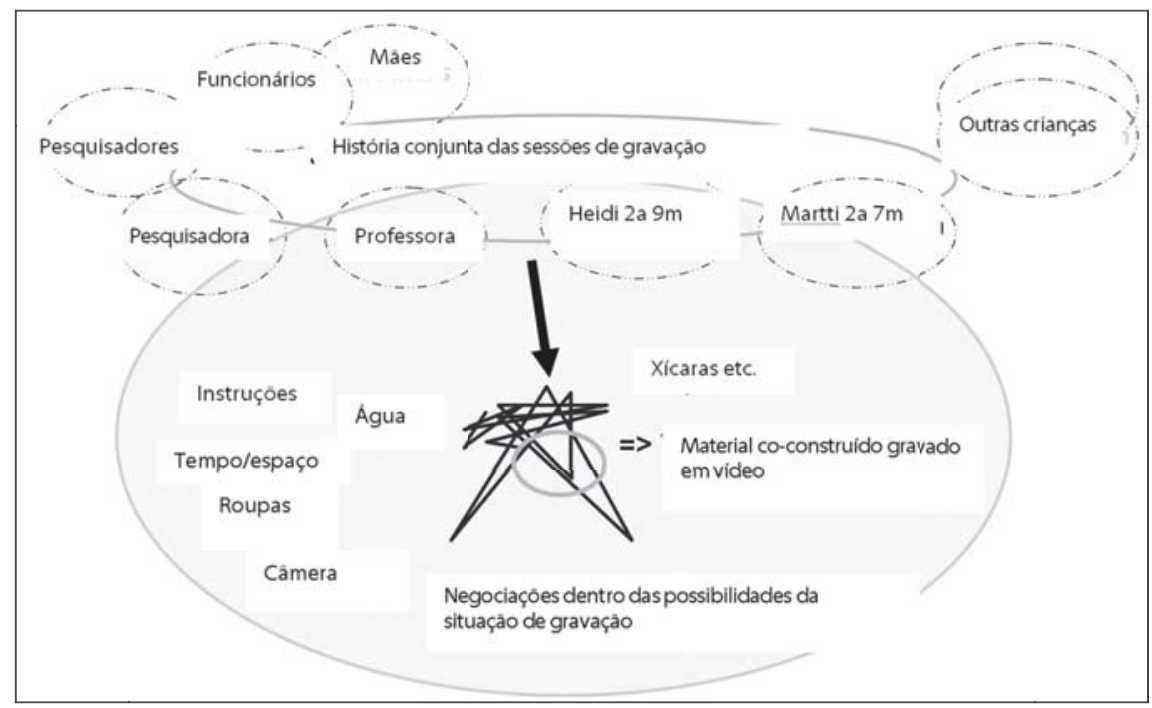

Figura 4. Negociações antes e durante a última sessão de gravação.

sas, machucava e deixava as crianças molhadas. Os outros pesquisadores, a equipe, as mães e as outras crianças continuaram sendo participantes indiretos, mas com menos ênfase por não estarem presentes nas situações nem participando da construção de significados durante o desenrolar do fluxo das ações.

\section{Observações finais}

Nesse artigo, apresentei achados de um estudo de caso de situações de gravação particulares que ocorreram em uma creche. $\mathrm{O}$ que a análise desse caso em particular mostra? Por que falar sobre a cultura das sessões de gravação?

Tornou-se claro que as gravações começaram a formar um contexto interpretativo particular para as ações, gestos e verbalizações das crianças. Da história e das experiências conjuntamente construídas surgiram um recorte e posições iniciais particulares para os participantes da sessão começarem as negociações dentro das sessões. A construção de sentidos estava intimamente ligada à situação material particular estabelecida nas gravações. Além disso, as sessões incluíram constância e repetitividade; em alguns momentos, os significados anteriormente estabelecidos foram reintroduzidos sem longas negociações. 
Ao longo do ano, as sessões incluíram negociação contínua de circunscritores para as ações. Os adultos organizaram o ambiente inicial e se engajaram em tentativas ativas para canalizar as ações das crianças durante as sessões. Por outro lado, as crianças se engajaram em resistir e em experimentar dentro dos limites pouco precisos do que era possível e permitido ocorrer. Elas criaram uma contracultura em relação às tentativas de estruturação. As posições foram mais complexas do que simplesmente crianças sendo observadas por adultos: as crianças também convidavam os adultos a se juntar a elas e questionavam a posição dos adultos como observadores passivos dirigindo-se a eles e mostrando-lhes os objetos.

\title{
Two-year-old children as co-constructors of culture
}

\begin{abstract}
How is culture coconstructed in the micro-level of everyday interactions in a day care center? What is the "culture" being constructed, who are the constructors and how? This paper is based on a case study of interaction among two-year-old children. For the study, video recordings were made twice a month during a period of seven months in a day care centre in Finland. In the recording sessions, the children were provided some objects to play with. Four sessions were selected for qualitative analysis. During the first session, the children produced a counter-culture to the teacher's attempts to structure the situation. Gestures, postures, and verbalizations among the children emerged from initially random movements. The meaning and the functions of these postures, movements and sounds changed during the flow of actions. Some of the movements and verbalizations were re-established again and elaborated further in the following recording sessions. The constraints for actions were continuously negotiated nonverbally and verbally among the children and the adults. The wider institutional culture of early childhood education wasn't a passive frame somewhere outside the flow of actions, but it gained concreteness in the here-and-now situations. The adults' expectations and intentions were materialized in the initiations and in the arrangements of the setting and canalized the children's possibilities for actions. From this basis, the children co-constructed novel movements and meanings outside the adults' sphere of expectation.
\end{abstract}

Keywords: Child-child interaction. Children. Co-construction of culture. Day care.

\section{Enfants de deux ans comme co-constructeurs de culture}

Résumé: Comment la culture se co-construit-elle au microniveau des interactions quotidiennes dans un service d'accueil de la petite enfance? Quelle est cette'culture'construite, qui sont les constructeurs et comment procédent-ils? 
L'article s'appuie sur une étude de cas portant sur les interactions entre enfants de deux ans. Pour cette étude, des enregistrements-vidéos ont été effectués deux fois par mois pendant sept mois dans un service d'accueil, en Finlande. Lors de ces enregistrements, les enfants avaient des objets avec lesquels jouer. Quatre séances ont été choisies pour l'analyse qualitative. Au cours de la premiére séance, les enfants ont produit une contreculture aux tentatives de l'enseignante pour structurer la situation. Les gestes, postures et verbalisations des enfants ont émergé de leurs premiéres conduites effectuées au hasard. La signification et les fonctions de ces postures, mouvements et sons se sont transformés au cours de leurs actions. Certains mouvements et verbalisations ont été ré-établis et élaborés plus avant, au cours des séances suivantes. Les contraintes de l'action ont été constamment négociées, de façon verbale et non-verbale, entre les enfants et les adultes. La culture institutionnelle plus large de la petite enfance ne fut pas un cadre passif, quelquepart à l'extérieur du déroulement des actions mais a gagné quelque chose de concret dans l'ici et maintenant des situations. Les attentes et intentions des adultes furent matérialisées dans les initiatives et les aménagements de la situation, et ont canalisé les possibilités des enfants pour l'action. A partir de là, les enfants ont co-construit des mouvements et significations nouveaux, en dehors des attentes des adultes.

Mots-clés: Interacción enfant-enfant. Enfants à deux ans. Co-construcción de la culture. Service d'accueil de la petite enfance.

\section{Niños de dos años como coconstructores de cultura}

Resumen: ¿Cómo se co-construye la cultura en el nivel micro de la interacción cotidiana en un centro infantil? ¿Cuál es la cultura que se construye, quienes son los constructores y como lo hacen? Este artculo se basa en un estudio de caso de la interacción entre niños de dos anos de edad. Para este estudio se hicieron grabaciones en video dos veces al mes durante un periodo de siete meses, en un centro infantil en Finlandia. En las sesiones grabadas se les proporcionó a los niños objetos para jugar. Cuatro sesiones fueron seleccionadas para los análisis. Durante la primera sesión, los niños produjeron una contra-cultura a los intentos de los maestros de estructurar la situación. Gestos, posturas y verbalizaciones entre los niños surgieron casualmente en los movimientos iniciales. El significado y las funciones de esas posturas, movimientos y sonidos cambiaron durante el flujo de las acciones. Algunos de esos movimientos y verbalizaciones fueron reestablecidos nuevamente y desarrollados aún más en las grabaciones posteriores. Las limitantes del accionar fueron continuamente negociados verbal y no verbalmente entre los niños y maestros. La amplia cultura institucional de la educación parvularia no era un marco pasivo de referencia al margen del flujo de las acciones, sino que se hacia concreta en el aqui-y-ahora de las situaciones. Las 
expectativas e intenciones de los adultos se materializaban en la iniciación y en el ordenamiento del contexto y canalizaban las posibilidades de actuar de los niños. Desde esta base los niños co-construían nuevos movimientos y significados al margen de las esferas de expectativas de los adultos.

Palabras-clave: Interacción de niños. Niños. Co-construcción de la cultura. Centro infantil.

\section{Referências}

Amorim, K. S. (2002). Concretização de discursos e práticas histórico-sociais em situações de freqüência de bebês a creche. Tese de Doutorado, Programa de Pós-Graduação em Medicina, Universidade de São Paulo, Ribeirão Preto, SP.

Branco, A. (1998). Cooperation, competition, and related issues: A co-constructive approach. In M. C. D. P. Lyra \& J. Valsiner (Eds.), Construction of psychological processes in interpersonal communication: Child development within culturally structured environments (Vol. 4, pp. 181-205) Stanford, CA: Ablex.

Carvalho, A. M. A., Imperio-Hamburger, A., \& Pedrosa, M. I. (1998). Interaction, regulation and correlation in the context of human development: Conceptual discussion and empirical examples. In M.C.D.P.Lyra \&J.Valsiner (Eds.), Construction of psychological processes in interpersonal communication: Child development within culturally structured environments (Vol. 4, pp.155-180). Stanford, CA: Ablex.

Corsaro, W. A. (2005). The sociology of childhood. Thousand Oaks, CA: Pine Forge Press.

Fogel, A. (1993). Developing through relationships: Origins of communication, self, and culture. Chicago: The University of Chicago Press.

Fogel, A., Koeyer, I., Bellagamba, F., \& Bell, H. (2002). The dialogical self in the first two years of life: embarking on a journey of discovery. Theory \& Psychology, 12(2), 191-205.

Hermans, H. J. M., \& Kempen, H. J. G. (1995). Body, mind and culture: The dialogical nature of mediated action. Culture \& Psychology, 1(1), 103-114.

Kindermann, T. A., \& Valsiner, J. (1989). Research strategies in culture-inclusive developmental psychology. In J. Valsiner (Ed.), Child development in cultural context (pp. 13-50). Göttingen/Toronto: Hogrefe.

Latour, B. (1996). On interobjectivity. Mind, culture and activity, 3(4), 228-245.

Oliveira, Z. M. R., \& Rossetti-Ferreira, M. C. (1996). Understanding the co-constructive nature of human development: Role coordination in early peer interaction. In J. Valsiner \& H-G. Voss (Eds.), The structure of learning processes (pp. 177-204). New Jersey: Ablex.

Pedrosa, M. I. (1989). Interação criança-criança: um lugar de construção do sujeito. Tese de Doutorado, Programa de Pós-Graduação em Psicologia, Universidade de São Paulo, São Paulo. 
Pedrosa, M. I., \& Carvalho, A. M. A. (2005). Análise qualitativa de episódios de interação: uma reflexão sobre procedimentos e formas de uso. Psicologia Reflexão e Crítica, 18(3), 431-442.

Pedrosa, M. I., Carvalho, A. M. A., \& Imperio-Hamburger, A. (1997). From disordered to ordered movement: Attractor configuration and development. In A. Fogel, M. C. D. P. Lyra \& J. Valsiner (Eds.), Dynamics and indeterminism in developmental and social processes (pp. 135-151). Mahwah, NJ: Erlbaum.

Rossetti-Ferreira, M. C., Amorim, K. S., Silva, A. P. S., \& Carvalho, A. M. A. (Orgs.). (2004). Rede de significações e o estudo do desenvolvimento humano. Porto Alegre: ArtMed.

Rutanen, N. (2004). Is there "free play"? Example of a researcher as constructing limits and possibilities for children's actions. Seminar The culture created by children and children's participation. Stakes, Helsinki, Finland. Recuperado em 09 de agosto de 2006, de http://www.edu.helsinki.fi/lapsetkertovat/lapset/In_English/ Rutanen.pdf

Rutanen, N. (2005). The emergence of novelty and constraints in two-year-old children's interactions. Paper presented at Children and culture - in theory and method? The Nordic Child Cultural Research Network, BIN-Norden-conference. Copenhagen, Denmark.

Rönnberg, M. (2005). Children's culture as counterculture: How the third sex opposes the first and second sex through children's culture. Keynote lecture at ChildhoodSummer School in Cultural Studies. University of Jyväskylä, Jyväskylä: Finland.

Valsiner, J. (1997). Culture and the development of children's action: A theory of human development. New York: John Wiley.

Niina Rutanen, Pesquisadora especial junto ao Departamento de Ciências Educacionais da Universidade de Jyväskylä, Finlândia, e atua como coordenadora do Finnish Network for Childhood Studies. Também é secretária da Finnish Society for Childhood Studies, fundada em 2008. Endereço para correspondência: Sammonkatu $32 \mathrm{~F}$ 75, 33540.Tampere, Finlândia. Endereço eletrônico: email: niina.rutanen@jyu.fi

Recebido em: 19/02/2009

Aceito em: 18/05/2009 